\title{
Resilience for Young People with Physical Motor Deficiency
}

\section{-A Study of Compensatory Features and Conducts}

\author{
Marinela Rusu (1) \\ Romanian Academy, Branch of Iași, ICES “Gh. Zane”, Iași, Romania \\ Email: marinela1808@yahoo.com
}

How to cite this paper: Rusu, M. (2019). Resilience for Young People with Physical Motor Deficiency. Psychology, 10, 844-863. https://doi.org/10.4236/psych.2019.106055

Received: March 4, 2019

Accepted: May 14, 2019

Published: May 17, 2019

Copyright () 2019 by author(s) and Scientific Research Publishing Inc. This work is licensed under the Creative Commons Attribution-NonCommercial International License (CC BY-NC 4.0). http://creativecommons.org/licenses/by-nc/4.0/ (c) (i) (8) Open Access

\begin{abstract}
Resilience is a complex concept that describes different ways to overcome traumatic situations, failures, or radical changes in life, understood to be an individual capacity to fight adversity. In this paper we propose two hypotheses in the case of adolescents with physical motor deficiency (PMD) ${ }^{1}$ : if positive elements can be identified in adolescent behavior with PMD, considered as components of resilience and if, by the psychological intervention, there was a better resilience. Psychological tests with deep resonance within the personality were applied: WM Personality Inventory, Introversion-Extraversion-Neurosis Test, DE-AN Questionnaire. There have been also used projective methods. Following the quantitative-statistical and qualitative analysis of the results obtained in the group of teenagers with PMD, were identified a series of specific traits and also some compensatory features along with compensatory conducts as elements of resilience. Resilience is interpreted through compensation (features and conducts), through individual and social valorisation, through integrating teenagers with PMD in school and social groups. Other related concepts are discussed: compensation and expectance, idolizing normality, labelling etc.
\end{abstract}

\section{Keywords}

Adolescents with Physical Motor Deficiency, Resilience, Compensatory Traits and Conducts, Labelling, Idolizing Normality, Positive Psychology

\section{Introduction}

The personality of adolescents with physical disabilities requires a complex approach that includes the need for a bilateral interpretation: on the one hand,

${ }^{1} \mathrm{PMD}$-abbreviation for "physical motor deficiency", used in this paper. 
there are interests in the personality of these young people, how is it structured relative to the deficiency, and secondly, there are concerns about the way in which these young people will be better integrated into the school group or in society.

Society's negative bias toward its members who have different disabilities is detrimental to the welfare and productive participation of this already marginalized and disadvantaged group. Although unfavorable attitudes are often covert, they are detectable "in the use of media stereotypes, prejudicial beliefs, derogatory labels, or lack of care for the well-being of disabled people" (Antonak \& Livneh, 1988: p. 14).

An experiment carried out a few years ago, which was continued in the form of the theoretical studies and research, reveals a number of useful elements in current investigative approaches. Our findings showed specific cognitive and affective traits, followed by changes in the behaviour and interpersonal relationships. Compensatory traits and behaviours are approached to counterbalance the negative aspects already crystallized at the level of their personality. All these compensations are vital elements in the resilience process.

\section{Previous Researches}

\subsection{Experimental Data}

Although there has not been much analysis in this area, we can still recall some important research, such as those of Spain, Dorner, Rowe, Rutter, or B. Wright. Research by Dorner $(1976,1977)$ and Rowe $(1973$, quoted by Dorner, 1977) on adolescents and young people with physical disabilities identified a series of features and behaviors strongly correlated with social isolation and marginalization. Young people have invoked as motivation of isolation, the transport difficulties, accessibility, and the overwhelming attention of others to their problem, which, according to the authors, requires accommodation time to no longer matter the indiscreet glances. Closely linked to the tendency to isolation, loneliness, feelings of depression and unhappiness have also been identified, lack of integration into a group of same-age friends (Dorner, 1976).

In Australia, McAndrew (1978) draws attention, among other things, to the psychological problems of adolescent with spina bifida. The final findings closely resemble Dorner's results: depression is a present feature, accompanied by mistrust themselves, lack of an ideal of life but also a low self-esteem. Other researches, made by Spain and his colleagues identified a marked lack of self-confidence in adolescents with physical disabilities, "general anxiety and fearfulness, coupled often, though not always, with misery and depression" (Spain et al., 1982: p. 108).

A complementary direction of the studies of adolescents with physical deficiencies is represented by the extensive research made by Rutter et al. (1976) on the psychological specificity of adolescent age. He finds elements of anxiety, depression or low self-esteem, to those without deficiencies as well as to the teens with deficiencies. Therefore, the author argues, the interpretation of the results 
in the case of deficiencies must be done with great discernment, taking into account the personal history of each adolescent, the traumatic experiences he/she has experienced throughout his/her life.

Finally, in order to better understand the deep feelings, emotions of inadequacy of adolescents with deficiencies we can return to a classical specialty literature such as: Goffman's Stigma (Goffman, 1963), Wright's Physical Disability, a psychological approach (Wright, 1960/1983) and Hunt's Stigma: the experience of physical disability (Hunt, 1960).

\subsection{The Concept of "Compensation"}

In his works "L'enfant difficile" (1970), "Le temperament nerveux" (1926) and "The Knowledge of Man" (1991), Alfred Adler $(1970,1926,1991)$ set the theoretical basis of a concept that would become famous in psychology: the concept of compensation which has not yet been modified in its essential data. Broadly speaking, compensation outlines the possibility of overcoming a functional disability or anomalies. The deficient function of an organ normally determines, Adler claims, a "power compensating will", thus influencing the conduct of the whole personality. Contrasting with Freudian sexual theory, Adler sees in psychic illness a social or antisocial outcome of a "discouraged" (of an adult who in his childhood was neglected, abandoned, or on the contrary, captured by an excess of affection or who was touched by inferiority which is directly related to the need to communicate, to co-operate). For Adler, the real conflict is at a social level. His special contribution is not the study of the complex of inferiority, but discovering how to find out the compensatory dynamism which proceeds from inferiority in a determined society. Being understood as a mechanism of counterbalancing a deficiency, dissatisfaction or lack of achievement, the concept of compensation was generalized by Adler for the entire psychological development of personality. Thus, the compensation acquires the character of a law of psychic life and designates that reaction to any type of personal lack. ${ }^{2}$ The sense of inferiority threatens the integrity of personalities, the latter defining unconsciously defensive attitudes: exaggerated sensitivity, excessive caution, pedantism, impertinence, reluctant spirit, dissatisfaction, impatience, combativeness. The aggressiveness, hostility that constitutional inferiority generates and accentuates, is intimately confused with the desire to be as powerful as others, and highlights the underlying traits of ambition.

\subsection{Deficiency and Specific Feelings}

The definition of a person with physical disabilities contains three elements: 1)

${ }^{2}$ Adler himself suffered from rickets, which stopped him from running, playing with the other children. This did not prevent him, however, to be very active and sociable, decided to become a doctor for "fighting with death". He was also considered totally unmatched in mathematics, but through perseverance he came from a poor mathematics student, the best in the classroom. So, the very creator of the concept of inferiority and of the one of compensation has lived through his own experience the processuality of this psychological phenomenon. (Pam Hirsch, quoted by Allen, F., Pearson, 1928: p. 137). 
the presence of an impairment; 2) the experience of externally imposed restrictions; 3) self-identification as a person with a physically deficiency (Oliver, 1996: p. 5). At the core of the reaction to deficiency is, Adler says, the sense of imperfection that drives and mobilizes the possibilities and depths of the body and guides them to compensate. Inferiority disadvantages, humiliates, hurts, places the person in the perspective of failure, defeat; the individual is anchored on his sense of inferiority, regardless of the fact that his/her deficiency is minor or major, that his/her dissatisfaction is real or presumed or felt without obvious reason. Despite his exaggeration on inferiority, generalized to the entire human species, Adler explains a process that can lead to personality optimization and to the success of resilience: the sense of inferiority can, however, be a source of individual realization, of individual progress, a source of evolution, development, triggered by the desire to compensate. Since the human body is built on "security principles" the disrupted functions of an organ can trigger a compensatory energy. Once established, the sense of inferiority becomes a kind of center around which the person is built, trying more or less consciously, to compensate that feeling, to annihilate its effects. In his works, Adler synthesizes two possible ways in this regard (Adler, 1970: p. 89):

- the emergence of imaginative conducts, the consoling reverie, the tendency of refuge and passivity;

- the emergence of an internal psychic energy manifested by the desire for power, brilliance, affirmation.

From the last possibility, the psychiatrist C. Gorgos (1992) comments, can emerge the creative will (or, as Adler says, "the will of power") and you can find it to writers, painters, generally to artists, or influencing sometimes negative behaviours such as: jealousy, domination tendencies, revenge, violence. When the individual's lifestyle is shaped by pursuing only the goal of overcoming his inferiority or personal lack of achievement, possible finding a diminishing social sentiment (understood as the ability to cooperate with others) with a high risk of installing neurosis. In his work "Le temperament nerveux", Adler (1926: p. 27) notes that "any organic inferiority influences the psychical integrity, affects activity and thinking, manifests itself in dreams, expresses in choosing a profession, in artistic tendencies and aptitudes."

\section{Hypothesis}

The first feature that defines the "human project" is, after Handley Cantril (1987: p. 53), "the need for physical and mental security necessary to protect the already accumulated acquisitions and to provide a platform on which it can then climb step by step." This is why a close proximity to the people with PMD is an obligation in the field of scientific investigation. As we have seen before, the psychological profile of deficient adolescents is often marked by feelings of diminishing self-esteem (Dorner, 1977) or the tendency to isolate and communicate as little as possible with others (Spain at al., 1982). Thus, collaboration with 
specialized adults, assistance and help from others is a means of re-adaptation, necessary for a good group integration. Compensatory traits and conducts are, in turn, the intimate, constitutive elements that improve their adaptability, resilience and integration. Taking all of these into account, in our research we have focused on the following hypothesis:

- which positive elements (traits and behaviors) can be identified in adolescent behaviors with PMD, that can be integrated as components of resilience and rehabilitation and also

- if, by quantitative and qualitative interpretation of the data obtained, could be noticed a better resilience and adaptation of these adolescents.

The context of the investigations, it imposed the use of both extensive methods and intensive procedures, all the more so since we have been pursuing a synthetic look, but also an analytical approach to affective perturbations and compensation deriving from this situation.

\section{Methods}

The experimental research was realized with a group (G1) of 52 participants (girls and boys) aged 15 - 17, from the Technical College "Ion Holban" of Iași, Romania, presenting different types of motor deficiencies (PMD) (Marie Charcot syndrome, spinal amyotrophic syndrome, progressive myopathy, spastic paraparesis, tetraparesis, planovalgic legs) and a group (G2) of 50 pupils without deficiencies, the same age, (the control group), from "Emil Racovita" High School of Iași (Romania). A methodological investigation was carried out, involving the application of a set of psychological tests with deep resonance within the personality (Woodworth-Mathews/WM Personality Inventory, Introversion-Extraversion-Neurosis/Eysenck Test, Depression-Anxiety Questionnaire/ DE-AN). There have been used projective methods that reflect the affective-motivational substrate of the personality of these teenagers: Koch-Storra Tree Test, Verbal Associative Experiment-extended form, Color Test (Lüscher), Real Motivation. Biographical Method was also included among the methods of investigation. The experiment was carried out in two stages: the first stage-quantitative (application of methods of investigation and the comparative, statistical interpretation) and the second stage-intervention, consisting in the application of the optimization methods: roll playing, autogenic training (Schultz \& Luthe, 1959; Wisiak \& Tschernegg, 2010) and drawing, followed by a qualitative interpretation.

\section{Results}

\subsection{Statistical Interpretation}

Part of the results obtained in the experiment realized with the participation of adolescents with PMD have already been published by the author in papers such as: Physical Motor Deficiency in Adolescence-A Psychological Profile From the Development Perspective or Adolescents With Physical Deficiencies-Between 
Tolerance And Rejection. Changing Negative Attitude (2018 a, b).

The statistical interpretation of the data obtained from the initial tests reveals key-aspects related to the psychological profile of adolescents with PMD and adolescents without deficiencies. The sample set was first applied to group G1 (with PMD) and then to control group G2 (without deficiencies). Next, there were highlighted the significant differences recorded by statistical results (Mann Whitney's significance test) emerged from the comparison of the data obtained from testing in the experimental group G1 and the G2, the control group (Rusu, 2002).

In a brief presentation of these results one can observe specific elements in the conduct and psychological profile of adolescents with PMD: teenagers in the first group are distinguished by the sadness, anxiety, lack of satisfaction, increased sensitivity and irritability that characterize them as compared to those without any deficiencies that are less affected by some conflicting situations, finding compensatory solutions easier, adapting to frustrating or devaluing situations (Table 1). Depression is strongly correlated with the other variables previously highlighted as significantly more pronounced for the experimental group than the control group, such as emotivity, anxiety, the presence of obsessions and phobias, and isolation tendencies towards the group (Table 2).

The synthesis of these data identifies that, on the one hand, there is a significant influence of motor deficiency in the development of psychic traits and specific behavioral reactions within the personality and, on the other hand, the claim that motor deficiency leads to the development of compensatory tendencies, features, psychic attributes and compensatory behavior is reflected in the

Table 1. Significant differences $\mathrm{G}_{1}-\mathrm{G}_{2}$

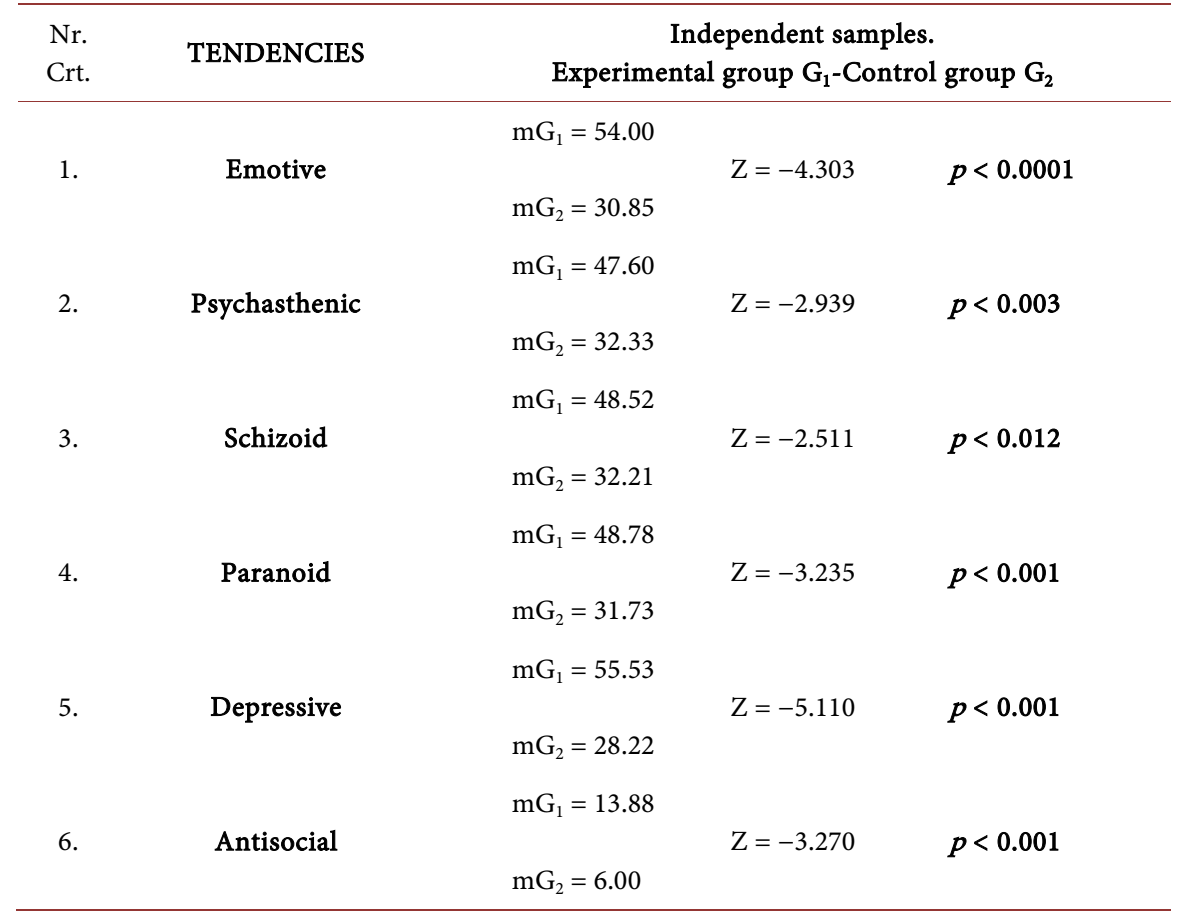


Table 2. DE-AN test. Significant differences $G_{1}-G_{2}$.

\begin{tabular}{cccc}
\hline DEPRESSION-ANXIETY & \multicolumn{3}{c}{ Independent samples. } \\
& \multicolumn{2}{c}{ Experimental group $\mathrm{G}_{1}$-Control group $\mathrm{G}_{2}$} \\
\hline Depression & $\mathrm{mG}_{1}=50.61$ & $\mathrm{Z}=-2.66$ & $p<0.007$ \\
& $\mathrm{mG}_{2}=45.26$ & \\
\hline $\begin{array}{c}\text { Introversion-Extraversion } \\
\text { Neurosis }\end{array}$ & \multicolumn{2}{c}{ Independent samples. } \\
Experimental group $\mathrm{G}_{1}$-Control group $\mathrm{G}_{2}$ \\
\hline Neurosis & $\mathrm{mG}_{1}=53.88$ & \\
& $\mathrm{mG}_{2}=32.39$ & $\mathrm{Z}=-3.970$ & $p<0.001$ \\
\hline
\end{tabular}

data interpretation. The statistical analysis revealed significant differences between the two groups in the various variables of the applied samples, such as: emotivity, the tendency towards isolation and psychasteny, depression, the tendency to aggression and the need for compensation, the level of neurosis and anxiety.

If statistical data has been discussed previously, helping to create a psychological profile for teenagers with PMD, in this paper it is paid special attention to the general result of the experiment, which takes into account the information gathered from the projective tests, the biographical method and from the observations made during the teenagers interviews.

\subsection{Qualitative Interpretation}

\section{Compensatory traits and conducts.}

The statistical analysis of the data obtained provided valuable help in detecting and explaining the compensatory tendencies in adolescents with physical deficiencies (Rusu, 2018a, 2018b). The emergence and development of both the sense of inferiority and the self-devaluation attitude is often caused by the confirmation of some failures in the past that tend to be reasserted more easily at present. It seems that any experience has a particular effect, which can be more or less constructive. However, thinking about the therapeutic approach-if only the frequency would be important-the situation would be unfortunate, because the therapy would then have the impossible purpose of modifying the situations and perceptions of an individual that were developed along a lifetime experience.

Thus, the compensation mechanism must overcome all these negative experiences at some point, establishing a new relationship to themselves, to their own physical deficiency, and to others. In this sense, compensation has to be interpreted as a stage of self-becoming, not as a universal element, as an explanation of any adaptive conduct. It is necessary a period of time until social skills are acquired and the adaptive process is oriented towards success.

As Williams (1983: p. 648) says "assessing an individual's physical functioning represents only one dimension of a functional which must also comprehensive assessment, touch the and mental social, emotional, upon well-being”. Compen- 
satory conduct will be understood as a result of the person's efforts to develop through his/her own strive, a positive trait and a proper behaviour. Thus, the compensation mechanism can act directly through the person by raising awareness and triggering a counter-mechanism. Compensation can also act indirectly through the school which can provide specific activities, corresponding to each person's own abilities, ensuring success. The compensatory mechanism can also work within the teacher-student relationship, where, by trusting the teacher and his support, self-perception can be improved. Last but not least, family relationships are a huge reserve for offsetting at the level of conduct, providing the teenager with PMD affection, acceptance and understanding.

The traits presented above are consistent with some well-known elements of resilience, and these include 1) psychological and dispositional attributes, 2) family support and cohesion, and 3) external support systems (Campbell-Sills et al., 2006; Connor \& Davidson, 2003; Friborg et al., 2003). First, psychological and dispositional attributes includes the factors of 1) personal competence, 2) social competence, and 3) personal structure. Personal competence can be defined as an individual's belief in ability, accomplishments, determination, and realistic perspective (e.g., "I can get through this traumatic event"; Friborg et al., 2003). Social competence is an individual's belief in his or her ability in social situations and consists of extraversion, social/communication skills, ability to initiate conversations, and social adaptability. Personal structure refers to an individual's ability to plan and organize daily activities (e.g., develop and maintain a personal schedule for activities of daily living). Second, family support and cohesion examines how families resolve conflict, cooperate to achieve goals, and maintain stability (e.g., family takes turns driving an individual to therapy). Third, external support systems refer to an individual's ability to give and receive support from family and friends and develop intimacy with those close to him or her (Friborg et al., 2003), which is recognized as playing an integral role in rehabilitation from a traumatic injury (Driver, Rees, O'Connor, \& Lox, 2006).

Our observations have indicated that the microgroup represents an excellent means for self-assertion and the crystallization of the future personality. In order to counterbalance mistrust, to overcome resentment and low self-esteem, to overcome envy and rivalry, compensation offers self-confidence enhancement, conscious cultivated, thorough knowledge of one's own qualities, talents and $a b$ ilities. The sense of culpability was also analysed (either in the group or only with the psychologist), becoming aware of its exogenous causes (negative suggestions, malicious remarks, etc.), without any real connection with physical deficiency. As a compensation for irritability and aggression was approached the cultivation of calmness and patient inner gaze. Withdrawal and isolation were connected in our discussions with the negative effects of shame, opposed to the courage of asserting in the micro-group, the boldness of "being yourself" as compensatory traits. As for the negative opinion of others, young people with physical disabilities have to understand its incoherence and injustice, born out of 
ignorance or the insensibility of others.

However, several important ideas of B. Wright's theory (quoted by Dunn \& Elliott, 2005: p. 185) have constituted theoretical frameworks for thinking in discussions with adolescents with PMD. These include:

1) individuals are worthy of dignity, respect, and encouragement, no matter how severe their disability;

2) the social and physical environment has profound consequences for coping and adjusting to a disability;

3) no matter the circumstance, all individuals possess unique, personal assets that can aid rehabilitation;

4) active involvement of clients as co-managers of rehabilitation has positive benefits for themselves and for practitioners;

5) psychological issues are constants throughout rehabilitation.

The feeling of frustration can be offset by cultivating the idea of psychic integrity, thus inducing a change in the hierarchy of personal values, moving towards the "decentralization of the physic". As Ausubel remarks: "The psychophysiological consequences of the deficiency will depend on the attitude of society and the individual towards non-conformism, the intensity of attitudes of self-acceptance and possession of compensatory means, but also of the particular meaning of deficiency for the individual" (1952: p. 102).

In the same sense, Beatrice Wright and her colleagues (Dembo, Ladieu-Leviton, \& Wright, 1956/1975) articulated value changes in acceptance of loss or disability as a) enlarging the scope of values, b) subordinating physique relative to other values, c) containing disability effects, and d) transforming comparative-status values into asset values. Ausubel (2002) developed the Acceptance of Disability Scale as a global measure derived from the theory of acceptance of loss by Wright and her colleagues (quoted by McCarthy, 2011: p. 69). All of these ideas have been addressed in discussions, repeatedly held with adolescents with PMD.

For example, many studies have shown that people with deficiency hate the deficiency of others because they hate theirs (Meisel, 1986). When a teenager poses a positive self-esteem, he sees the "long look" of others as a "mere curiosity" about how he/she manages the crutches etc. and the sense of shame is dominated. If the adolescent rejects the deficiency and himself, he/she will tend to resist the curiosity of others, feeling that is perceived negatively, with aversion and mercy. Negative self-image makes him/her an "object of stimulus for others" (Wright, 1988: p. 12). In this situation, the adolescent will also refuse to discuss deficiency by shaping a mask of inferiority, hiding his physical defect. The "situational context" factor has a great importance in determining the person's reaction. The refusal to discuss reflects the idea that the relationship with others is a violation of his/her personal life.

Many times, in the discussions that took place with the teenagers participants in the experiment, has been approached the idea that the "personal context" offers the chance of compensatory behaviour by going beyond the assertion that "I 
am deficient" to "not me but my deficiency", reinforcing the truth that the personal skills, talents and abilities are more important than the physical aspect. In fact, "Your abilities are more than your deficiencies," says an exhortation of the specialists from the New York Institute of Physics (apud Păunescu, 1983: p. 112). The tendency to be and to appear "as if" nothing would have happened was a compensatory behaviour that the adolescents participating in the discussion group they recognized it as hiding, in fact, a great deal of resistance to talk about deficiency.

The presence of some psychiatric/affective symptoms or tendencies (e.g., depression, anxiety) are associated, say researchers in resilience and rehabilitation, with the absence of resilience and dysfunctional reintegration. Finally, results indicated a relationship between resilience and personality. "All subscales correlated with measures of personality, suggesting that if a person measures high in personal strength or social competence (e.g., personality traits), then they are likely to have a coherent and stable family or social support network (e.g., resilient qualities)" (White et al., 2008: p. 34).

Other key findings from the resilience literature, useful in the conducted investigation, indicates that (a) the skills associated with resilience are ordinary in nature, not heroic or superhuman, and (b) the skills are modifiable and can be learned (Newman, 2005).

Making a synthesis of previous discussions on the psychological profile of teenagers with motor deficiencies as well as the traits of compensatory conduct identified, there can described the following ways in which the process of rehabilitation should be improved: favouring discussion about deficiency with security providers; integration into a group in which they are accepted without being judged; reassurance of their merits as a person or the fact that their attitudes and behaviour towards others are justified.

Referring to the positive psychology of Beatrice Wright (1983) can be mentioned here the positive resources within the person and the situation, including emphasis "on assets of the person rather than the limitations; focus on similarities rather than differences between persons with a disability (PWDs) and those without; the value of hope in adjusting to disability or misfortune or suffering; and demonstration that a disabling condition does not spell the end of a life worth living" (1983: p. 58).

As a corollary of the interpretation, the discussions with adolescents with PMD, revealed that compensatory conducts has an important effect on re-evaluating self-image and reducing frustration, to regain a degree of independence from the environment; this can be accomplished by providing suitable conditions and some material aids: prostheses, crutches, moving racks, special baths, rolling ramps, wheelchairs with automatic controls etc.

Table 3 presents a comparative synthesis of the compensatory traits and conducts proposed in the experimental intervention for the adolescents with PMD, comparative to the traits and conducts already identified during the first part of the experiment. Compensatory traits and conducts are presented as 
Table 3. Compensatory traits and conducts.

\section{Nr. crt. Compensatory traits and conducts proposed versus traits and conducts identified.}

1. Self-confidence (through self-knowledge of qualities, talents and personal abilities) versus self-distrust, resentment, dissatisfaction, envy, rivalry;

2. Conscious analysis of exogenous causes of the feeling of guilt versus feeling guilty, to be a victim;

3. Cultivating calm and introspection versus irritability, aggression;

4. Cultivating the courage of being "yourself"; analysing marginalization and isolation as "contextual factors" versus withdrawal and isolation;

5. Awareness of the negative opinion of others as a result of ignorance and insensitivity versus being a victim, suffering due to the depreciative, negative opinion of others;

6. Changing the personal hierarchy of values - "Physical decentralization", "The courage of non-conformism", accentuating mental integrity versus feelings of frustration due to the functional limitations;

7. Acceptance in the family, in group; reassurance over their merits versus affective, vocational frustration;

8. Acceptance of deficiency and self-acceptance versus rejecting, denying and hiding deficiency;

9. Conduct in an impersonal context. "I am a person with a deficiency" versus conduct in a personal context: "I am deficient";

10. Regaining a degree of independence from the environment. Group reassurance over their merits versus being dependent on others.

elements of resilience improving rehabilitation and social integration:

In addition to these features and behaviours for teenagers with PMD, there are some adverse reactions to the physical differences due to the deficiency that have been identified (Rusu, 1995: pp. 12-18): refusal or denial that the deficiency exists or the fact that it involves a certain kind of limitations; resignation or renunciation signifies hopeless, accompanied by the refusal to help him/herself or to be helped by others; self-perception as a victim of an injustice perpetuated by others, manifested by punishing "the others" through hostility and isolation; the manifestation of arrogance and aggression, refusing aid or empathy, manifesting an aggressive claiming attitude; perceiving the deficiency as a punishment for real or imaginary violation of family or society rules; becoming addictive and reluctant because the helplessness seems to be the only way to ensure attention, affection, and care.

During the investigation, it was determined that the tendency to isolate themselves from society and micro-group was compensated by the affirmation of sincere, secure relations with intimate, close friends, to whom the most hidden thoughts, the personal embarrassment can be revealed, all these being reflected in the answers of the participants.

The findings made in the experiment, showed that the person with physical deficiencies faces two essential psychological problems: to understand the nature of their own deficiency and then to become as independent as possible, yet hav- 
ing that deficiency. The superficial recognition of a deficiency, the extreme minimization of its symptoms, can often mask subconscious self-rejection, inner dissatisfaction, anger, or unrealistic expectations that deny that condition or use it to exploit others. To circumvent these maladaptive patterns, adolescents with physical disabilities must be surrounded by adults who accept deficiency as a limitation, but who refuse to turn it into a punishment or an excuse.

\section{Compensation and Expectation}

In many studies there is approached the phenomenon of idolatry of normality standards (Wright, 1991), which is an element of the tendency towards perfectionism. The differences in the subjective appreciation of the severity of a disability are largely determined by individual personality coordinates (for example, for a violinist, losing a finger is a disability, for a driver, the same does not mean a disability at all). The perfectionism found within the tested group refers to a strong need for existential compensation. This is the case for a subject (P.N.) who after eight operations on both knees dreams, not to go well, but "to have perfect legs!" The hope of being "normal" and personal efforts to forget or cover the deficiency have important consequences on the standards and values that guide their own behaviour and assessments. That is why during the experiment it was often identified an unrealistic self-justification, some of the adolescents with PMD considered themselves victims who have been deceived or punished by others, confusing this drama with reality, trying to convince themselves that failure to achieve a position and recognition is the fault of others. It is understandable that in the case of deficiency, the person cannot simply revise the standards that determine his aspirations and how he perceives things.

Adolescents with motor deficiencies follow the "normal" majority standards for very different reasons. The need to act "as if" the deficiency would not exist is part of a primitive effort to compensate for that limitation. In this case, they will act as a person without deficiency, as far as possible. The concepts and ideals of others are taken as such, in other words, the standards of behaviour relevant to those without disabilities are maintained or taken as ideal, as a guide to one's own conduct, to establish relationships with others. Trying to achieve "normal" performance as a behavioural model—to become perfect as physical aspect—will produce an increase in the sense of failure and inferiority.

Idolizing normality, is a concept well integrated in the B. Wright's positive psychology regarding the rehabilitation of the persons with physical deficiency. The well-known researcher noted that in this situation the person "is idolizing normal standards... arbitrarily holding up 'normal' performance as the model of behavior" (Wright, 1983: p. 25).

When certain standards become ingrained in social thinking as the "right" way to accomplish tasks, there are demeaning or restrictive consequences for people who internalize the implied message of inferiority because they have to do things differently due to a disability. 
This possible psychological response can be particularly problematic in early stages of adjusting to an acquired disability, when past standards of behavior are still clung to, a stance that clearly interferes with a person's accomplishing the value shifts that Wright proposed would facilitate acceptance of disability as non-devaluating. Ableismis evident when social groups or systems adhere to behavioral expectations that are based on normative ablebodied functioning and that are assumed, implied, or mandated to be the only acceptable way to conduct oneself (Wright, 1991: p. 472). Our ableist thinking allowed us until not long ago to accept that having stairs at the entrance of a building was a given, even after we started building ramps at the delivery entrance to make that process more convenient; it also leads us to believe that walking independently is superior to using a cane or a wheelchair.

Wright's emphasis on positive aspects and approaches is the category label. A quote that captures a personal dimension of that influence states: "Her emphasis on the person and not on the disability complemented very nicely, not only those aspects of person centered counseling that I respect most highly, but also my frequently stated belief that we are counselors or psychologists in rehabilitation settings and not so-called 'rehabilitationists'" (quoted by McCarthy, 2011: p. 54).

She also proposed a conceptualization of labeling and its impact, of sensitivity to disabling language and advocating the use of "people first" language in the 1960s-long before the expression "people first" was even used.

Careful experimental research has shown that the experience of success and failure is largely unaffected by the performance of the individual, but is determined by his goals, expectations, and aspirations (White, 1979; Oliver, 1996). People usually raise their aspirations very close to their own possibilities. After success, goals are usually high. After failure, their level is lowered. In other words, the level of aspiration acts as a protective mechanism, so that most people, regardless of their abilities, experience success more and more. Research by Ralf Schwarzer (1992) confirms the same idea of the level of aspiration and expectation that leads to failure or success, adding to it the self-image that can be truly justified and valued, or on the contrary justified unrealistically, the individual becoming incapable to use the positive attributes they possess because of self-defeating beliefs.

And yet, through the discussions with the teenagers with PMD has been revealed that if the subject triumphs over severe difficulties, his/her sense of accomplishment, in situations where normal standards remain exemplary, such as relationships with adolescents of the opposite sex, is painfully hurt by a sense of shame and helplessness. It would seem that there is a point above which the subject cannot pass. Girls who have undergone recuperatory surgery, initially had the only aspiration to walk without crutches or support. After several successful interventions, their aspiration turned into the desire to walk perfectly and have "perfect feet". What, for the first stage, had been seen as an accomplishment, as a progress, immediately became a failure, because now, the "normal 
standards" to walk and the typical female image, were glorified in a new assertion: "This is how I should be, this is how I should walk."

Moreover, Franz Alexander (1970: p. 23) notes that "feelings of guilt and inferiority tend to strengthen each other." The person tries to get rid of the feeling of inferiority through denial and "as if" conduct through ambitious competition, through resentment against an unfair world that will make him/her feel guilty because of the new mistakes. Trying to get rid of the feeling of guilt will be achieved by strengthening, supplementing or inhibiting additional aggression. But this behavior that tries to bypass Scylla of feelings of inferiority will lead the teenager to the Charybda of feelings of guilt. The "normal" standards can have the value of a moral imputation. Here appears the shame and the guilt of violating the ethical code. Idolizing normal standards, place the subject to a lower position in terms of particular characteristics, but also of moral hierarchy.

An element around which discussions on standards of normality gain strong significance is the use of prostheses. It has been found that at a young age they are vehemently rejected. With the development of self-consciousness and integration into micro-groups, shame intervene and they are required much more (Wright, 1983). However, acting as a "normal person" is not the same as "feeling normal," which makes standards for people with disabilities somewhat different from those of people without disabilities.

S. Linton (1998) insisted on the idea that we cannot speak of similarity, identity, normality (as pattern, template) in the case of human beings. This is confirmed by the diversity of configurations of individual features, qualities or decreases that lead to success or adaptive failure. In some philosophies of re-adaptation, it is stated that instead of normal behaviour-as the gold guide for "what to do and how to do"-the abilities and deficiencies of a person will be put into action, and thus he/she will be really fulfilled. In the brochure dedicated to patients at the Institute for Physical Medicine and Rehabilitation in England there is an excellent remark: "There are hundreds of ways to do all these things that help us become independent. Maybe with your deficiency, you will not be able to do it the way others do, but it certainly does not mean you cannot learn to do it in a different way. That's why our people are here to teach you to do these things as best as possible with your deficiency" (quoted by Păunescu, 1983: p. 82).

\section{Positive Attitudes in Resilience and Rehabilitation}

To understand clearly what a person can accomplish is an important goal for successful integration of any person and is even more significant for people with physical disabilities. During the sessions of group-discussions, at least three distinct dimensions of this goal were pursued: to reach acceptance of limitations; to become aware of personal potentials and abilities as clearly as possible; to make sustained efforts to get improvements wherever possible.

The first two dimensions require rationality, while the third involves focusing 
on self-actualization. But all of these goals are not beyond any risk, and they are asking for new ways to solve the problems. In order to know the limits of someone, their abilities and their potential, what he/she can acquire is necessary for repeated assessments and continuous re-evaluations (Rusu, 1995). The tendency towards self-actualization essentially comprises two attitudes towards oneself, namely: a realistic self-concept that includes both positive and negative attributes, rather than fantasies related to personal impotence or omnipotence; and firm feelings of adequacy and confidentiality based on the person's actual ability to function in the individual, social, educational, and vocational fields.

Here are some of the positive attitudes that favour the psychological adaptation of adolescents with motor deficiencies, which were also described within the intervention:

- Acceptance of the deficiency.

- Knowing the limitations involves recognizing the means and possibilities that the young possess.

- Have and maintain expectations for performance and personal achievement.

- Bypassing comparisons with other young people and setting a standard in line with personal potential. Expecting more than a young can become frustrating, giving rise to a sense of loss and failure. Expecting too little, sometimes leads to excessive addiction, feelings of helplessness and resignation.

- Support and encourage the child's desire for independence. Children with disabilities tend to stay a lot longer dependent on their parents. That is why the greater the number of independent activities they can do, the more their physical deficiencies will be less disabling.

- Making a variety of experiences in the area of child's potential. While helping the child to develop his or her skills in the very realm where he is deficient, the parent or teacher will also encourage greater physical strength.

- Providing an own discipline tailored to individual possibilities.

Among the attitudes that favour a good psychological rehabilitation is the attitude of adults, that meets the specific needs of adolescents with physical deficiencies. Knowing the specifics of this age and psychological profile of adolescents with PMD it can be outlined the main special needs:

- the need for intimacy-developing the sexual maturity and corresponding interest and curiosity, together with the need for self-exploration, experimentation with others;

- the need for participation: treating the teenager as a child, excluding him/her from the discussions and decisions, that directly affect his or her future, it will not only be an insult to his/her effort to be more independent, but will also maintain dependence, even producing psychic states of regression;

- the need for confidentiality: reflects the need for the teenager to confirm his or her own abilities and at the same time to shape realistic goals for the future;

- the need for knowledge: the teenager will seek to understand his/her own deficiency in terms of individual, social and vocational implications. 
Teachers will communicate as often as possible with their parents, helping them overcome their own fears and anxieties. They have to become capable of realizing a sincere communication, open to their own children, reaching out to the full understanding of the typical problems that arise in various situations.

\section{Conclusion and Recommendation}

Following the quantitative-statistical and qualitative analysis of the results obtained in the group of teenagers with physical motor deficiencies, were identified a series of specific traits and also some compensatory features:

- distrust, negative emotional tone, vocational frustration;

- compensatory conducts as resilience elements were identified: reading, listening to music, creative activities, compensatory conducts in the experimental group were strongly stimulated by school activities (for example, tailoring workshops, rehabilitation gymnasium, painting workshop, housekeeping workshop);

- results showed that most subjects experience abnormal psychological tension, which makes it difficult to develop a positive, socially valued compensatory behaviour without a specialized help from others.

Numerous positive compensatory features were encountered in our investigation:

- sincerity, self-giving, desire not to hurt anyone (not to make someone else suffer), appreciating others without making social or aesthetics judgments, as others do for them; sometimes there is the fear of not being compassionate enough, because they are agitated, irritable, wanting to change, to be calmer, more communicative; there is also the feeling of justice, honor, individual dignity (rejection of mercy) and the desire to help others.

Addressing the phenomenon of disability involves:

- new constructive perspectives that go beyond the field of education but also of training or research in the field of rehabilitation psychology;

- interdisciplinary efforts have a special importance in addressing the deficiency;

- bringing a new positive and activist perspective on the deficiency (e.g., White, 1979; Davis, 1997; Olkin \& Pledger, 2003). New visions of deficiency should be integrated into psychological training programs and deficiency projects (Asch \& Fine, 1988; Dunn \& Elliott, 2005).

In recent years, a series of legislative changes, as well as the movement that challenges the rights of people with disabilities (Charlton, 1998), have drawn public attention to the rights and social roles that can be met by people with physical disabilities (e.g., Americans with Disabilities Act, 1990/1991). Assessing the physical functioning of an individual refers to only one dimension of his general functionality so that, it needs to be a comprehensive assessment, to encompass his/her social mentality, emotional state and individual well-being (Williams 1983, quoted by Cornoni-Huntley et al., 1985: p. 358): 
- the goal of any rehabilitation program is to achieve the maximum function and adjustment of the individual and to prepare him physically, mentally, socially and vocationally "for the fullest possible life compatible with his abilities and disabilities" (Deaver, 1947: p. 311);

- in the establishment of any rehabilitation project it must be realized that industry is the keystone in the whole structure because industry must take the finished product and, by careful and selective placement, utilize these individuals within their capabilities; in both editions of Physical Disability, Beatrice Wright (1983) highlighted fundamental rehabilitative concepts that illustrate the need to emphasize people as individuals, not conditions or collectives. "An essential core-concept of human dignity is that a person is not an object, not a thing” (Dunn \& Elliott, 2005: p. 185);

- in the same sense, a significant statement is that disability is one of the many forms in which human life occurs: it should be accepted as such and the people concerned should not be excluded in any way from participating in society;

- disability policies must be based on an overall view of people and must take equal account of their physical, mental, emotional and social needs. It should therefore be oriented towards some important principles such as:

○ integration-participating in society to the largest extent possible;

- self-determination-to make their own decisions;

- helping people to help themselves;

- assistance oriented towards reinforcing the abilities of people with disabilities and their social environment and enabling them to achieve as much independence as possible;

- rehabilitation and integration of people with disabilities: policy and legislation;

○ customisation;

- accessibility of the assistance provided to the people concerned through information and advice (Council of Europe, 2003: pp. 11-12).

The present study can be complemented by further studies that can integrate the more detailed analysis of individual personality traits in relation to personal life experience, as well as a clearer comparative analysis with teenagers without deficiencies, emphasizing also common elements of their psychological profile.

\section{Conflicts of Interest}

The author declares no conflicts of interest regarding the publication of this paper.

\section{References}

Adler, A. (1926). Le temperament nerveux (pp. 27, 89). Paris: Payot.

Adler, A. (1970). L'enfant difficile. Paris: Payot.

Adler, A. (1991). Cunoaştereaomului. Bucureşti: Ed. Ştiințifică. 
Alexander, F. (1970). La medicine psychosomatique (p. 23). Paris: Payot.

Allen, F. H., \& Pearson, G. H. J. (1928). The Emotional Problems of the Physically Handicapped Child. British Journal of Medical Psychology, 8, 212-235.

Americans with Disabilities Act (1990/1991). Americans with Disabilities Act of 1990, Pub. L. No. 101-336, 104 Stat. 328.

https://www.eeoc.gov/eeoc/history/35th/1990s/ada.html

Antonak, R. F., \& Livneh, H. (1988). The Measurement of Attitudes toward People with Disabilities: Methods, Psychometrics and Scales (p. 14). Springfield, IL: Charles C Thomas.

Asch, A., \& Fine, M. (1988). Moving Disability beyond "Stigma”. Journal of Social Issues, 44, 3-21.

Ausubel, D. P. (2002). Theory and Problems of Adolescent Development (3rd ed., p. 102). Lincoln, NY, Shanghai: Writers Club Press.

Campbell-Sills, L., Cohan, S. L., \& Stein, M. B. (2006). Relationship of Resilience to Personality, Coping, and Psychiatric Symptoms in Young Adults. Behaviour Research and Therapy, 44, 585-599. https://doi.org/10.1016/j.brat.2005.05.001

Cantril, H. (1987). The Concept of Transaction in Psychology and Neurology (p. 53). New York: Mcmillan.

Charlton, J. I. (1998). Nothing about Us without Us: Disability Oppression and Empowerment. Berkeley, CA: University of California Press. https://doi.org/10.1525/california/9780520207950.001.0001

Connor, K. M., \& Davidson, J. R. T. (2003). Development of a New Resilience Scale: The Connor-Davidson Resilience Scale (CD-RISC). Depression and Anxiety, 18, 76-82.

https://doi.org/10.1002/da.10113

Cornoni-Huntley, D. J., Foley, L. R., Suzman, R., White, R. S., Berkman, L. F., Evans, D. A., \& Wallace, R. B. (1985). Epidemiology of Disability in the Oldest Old: Methodologic Issues and Preliminary Findings. The Milbank Memorial Fund Quarterly: Health and Society, 63, 350-376. https://doi.org/10.2307/3349884

Council of Europe (2003). Rehabilitation and Integration of People with Disabilities: Policy and Legislation (7th ed., pp. 11-12). https://rm.coe.int/16805a2a15 https://doi.org/10.1055/s-0038-1648547

Davis, L. J. (1997). The Disability Studies Reader. London: Routledge.

Deaver, G. G. (1947). Physical Rehabilitation of Disabled Persons. The New England Journal of Medicine, 236, 311-314. https://doi.org/10.1056/NEJM194702272360902

Dembo, T., Leviton, G. L., \& Wright, B. A. (1956/1975). Adjustment to Misfortune: A Problem of Social-Psychological Rehabilitation. Artificial Limbs, 3, 4-62.

Dorner, S. (1976). Adolescents with Spina Bifida, How They See Their Situation. Archives of Diseases in Childhood, 5, 439-444. https://doi.org/10.1136/adc.51.6.439

Dorner, S. (1977). Sexual Interest and Activity in Adolescents with Spina Bifida. Journal of Child Psychology and Psychiatry, 18, 229-307. https://doi.org/10.1111/j.1469-7610.1977.tb00435.x

Driver, S., Rees, K., O’Connor, J., \& Lox, C. J. (2006). Aquatics, Health Promoting Self-Care Behaviors and Adults with Brain Injuries. Brain Injury, 20, 133-141. https://doi.org/10.1080/02699050500443822

Dunn, D., \& Elliott, T. (2005). Revisiting a Constructive Classic: Wright's Physical Disability: A Psychosocial Approach. Rehabilitation Psychology, 50, 183-189.

https://doi.org/10.1037/0090-5550.50.2.183 
Friborg, O., Hjemdal, O., Rosenvinge, J. H., \& Martinussen, M. (2003). A New Rating Scale for Adult Resilience: What Are the Central Protective Resources behind Healthy Adjustment? International Journal of Methods in Psychiatric Research, 12, 65-76. https://doi.org/10.1002/mpr.143

Goffman, E. (1963). Stigma: Notes on the Management of Spoiled Identity. Upper Saddle River, NJ: Prentice-Hall.

Gorgos, C. (1992). Dicţionar Enciclopedic de Psihiatrie (Vol. I şi IV). Bucureşti: Ed. Medicală.

Hunt, P. (1960). Stigma: The Experience of Disability. London: Geoffrey Chapman.

Linton, S. (1998). Claiming Disability: Knowledge and Identity. New York: New York University Press.

McAndrew, I. (1978). Adolescents and Young People with Spina Bifida (p. 211). Melbourne: Ability Press, Royal Children's Hospital.

McCarthy, H. (2011). A Modest Festschrift and Insider Perspective on Beatrice Wright's Contributions to Rehabilitation Theory and Practice. Rehabilitation Counseling Bulletin, 54, 67-81. http://www.sagepub.com/journalsPermissions.nav https://doi.org/10.1177/0034355210386971

Meisel, J. C. (1986). Mainstreaming Handicapped Children: Outcomes, Controversies, and New Directions. Hillsdale, NJ: Lawrence Erlbaum Associates.

Newman, R. (2005). APA's Resilience Initiative. Professional Psychology: Research and Practice, 36, 227-229. https://doi.org/10.1037/0735-7028.36.3.227

Oliver, M. (1996). Understanding Disability: From Theory to Practice (p. 5). New York: Macmillian Education.

Olkin, R., \& Pledger, C. (2003). Can Disability Studies and Psychology Join Hands? American Psychologist, 58, 296-304. https://doi.org/10.1037/0003-066X.58.4.296

Păunescu, C. (1983). Copilul Deficient-Cunoaşterea şi educarea lui (p. 112). Bucureşti: Ed. Ştiințifică şi Enciclopedică.

Rusu, M. (1995). Conduitecompensatorii la adolescențiideficiențifizic (nr. 1, pp. 12-18). București: Educațiaspecială.

Rusu, M. (2002). Trăiriafectiveşicompensări (p. 187). Bucureşti: EdituraSapientia.

Rusu, M. (2018a). Physical Motor Deficiency in Adolescence-A Psychological Profile From the Development Perspective. Journal Psychological Review, 125, 975-993. https://psycnet.apa.org/PsycARTICLES/journal/rev/64/1

Rusu, M. (2018b). Adolescents with Physical Deficiencies-Between Tolerance and Rejection Changing Negative Attitude. Asian Journal of Social Sciences and Management Studies, 5, 123-130. https://doi.org/10.20448/journal.500.2018.53.123.130 http://www.asianonlinejournals.com/index.php/AJSSMS/article/view/1484

Rutter, M., Graham, P., Chadwick, O. F. D., \& Yule, W. (1976). Adolescent Turmoil: Fact or Fiction? Journal of Child Psychology and Psychiatry, 17, 35-56. https://doi.org/10.1111/j.1469-7610.1976.tb00372.x

Schultz, J. H., \& Luthe, W. (1959). Autogenic Training: A Physiological Approach in Psychotherapy. New York: Grune \& Stratton.

Schwarzer, R. (1992). Self-Efficacy as a Resource Factor in Stress Appraisal Processes. In R. Schwarzer (Ed.), Self-Efficacy: Thought Control of Action (pp. 195-213). Washington DC: Hemisphere.

Spain, B., Anderson, E. M., \& Clarke, L. (1982). Disability in Adolescence (pp. 108-112). London: Methuen. https://doi.org/10.4324/9780203472774 
White, B. (1979). Understanding Persons with Disabilities. Lincoln, NE: Lincoln Public Schools.

White, B., Driver, S., \& Warren, A.-M. (2008). Considering Resilience in the Rehabilitation of People with Traumatic Disabilities. Rehabilitation Psychology, 53, 9-17. https://doi.org/10.1037/0090-5550.53.1.9

Williams, T. F. (1983). Comprehensive Functional Assessment: An Overview. The Journal of American Geriatrics Society, 31, 637-641. https://doi.org/10.1111/j.1532-5415.1983.tb04148.x

Wisiak, U. V., \& Tschernegg, M. (2010). Autogenic Training. http://www.propaedeutikum-graz.at/download/Wisiak_AT_Folien_SS10.pdf

Wright, B. (1983). Physical Disability: A Psychosocial Approach (2nd ed., p. 25). New York: Harper \& Row. https://doi.org/10.1037/10589-000

Wright, B. A. (1988). Attitudes and the Fundamental Negative Bias: Conditions and Corrections. In H. E. Yuker (Ed.), Attitudes toward Persons with Disabilities (pp. 3-21). New York: Springer.

Wright, B. A. (1991). Labeling: The Need for Greater Person-Environment Individuation. In C. R. Snyder, \& D. R. Forsyth (Eds.), Handbook of Social and Clinical Psychology (pp. 469-487). New York: Pergamon Press. 